\title{
Differential long-term retention of biological disease- modifying antirheumatic drugs in patients with rheumatoid arthritis by age group: an observational study
}

\section{Akio Kawabe}

University of Occupational and Environmental Health, Japan

\section{Kazuhisa Nakano}

University of Occupational and Environmental Health, Japan

\section{Satoshi Kubo}

University of Occupational and Environmental Health, Japan

\section{Takeshi Asakawa}

University of Occupational and Environmental Health, Japan

Yoshiya Tanaka ( $\nabla$ tanaka@med.uoeh-u.ac.jp)

University of Occupation and Environmental Health, Japan https://orcid.org/0000-0002-0807-7139

\section{Research article}

Keywords: RA, bDMARDs, Retention rate, IPTW, Generalized propensity score

Posted Date: February 14th, 2020

DOl: https://doi.org/10.21203/rs.2.23604/v1

License: (c) (i) This work is licensed under a Creative Commons Attribution 4.0 International License. Read Full License

Version of Record: A version of this preprint was published at Arthritis Research \& Therapy on June 8th, 2020. See the published version at https://doi.org/10.1186/s13075-020-02233-9. 


\section{Abstract}

Background. The effectiveness and safety of biological disease-modifying antirheumatic drugs (bDMARDs) by age group $(<65,65-74$, and $\geq 75$ years) are uncertain. We examined retention rates reflecting the effectiveness and safety of bDMARDs in actual clinical practice for clarifying optimal therapeutic strategies for rheumatoid arthritis (RA) by age groups.

Methods. Data of patients who were treated with tumor necrosis factor inhibitors (TNFi), abatacept (ABA), and tocilizumab (TCZ) between February 2011 and April 2017 were retrospectively collected from an observational registry of RA patients. A total of 1,362 patients were enrolled, of which 695 were aged $<65$ years, 402 were aged $65-74$ years, and 265 were aged $\geq 75$. Primary outcome was the drug retention rate in adjusted data using inverse probability of treatment weighting based on generalized propensity scores.

Results. In patients aged $<65$ years, three-year retention rates of $\mathrm{TNFi}, \mathrm{ABA}$, and $\mathrm{TCZ}$ were $43 \%, 47 \%$, and $69 \%$, respectively (ABA versus TCZ, $p=0.017$; TNFi versus TCZ, $p=0.002$ ). In patients aged $65-74$ years, three-year retention rates of $\mathrm{TNFi}, \mathrm{ABA}$, and $\mathrm{TCZ}$ were $44 \%, 53 \%$, and $60 \%$, respectively (TCZ versus $\mathrm{TNFi}, p=0.034$ ). In patients aged $\geq 75$ years, three-year retention rates for $\mathrm{TNFi}, \mathrm{ABA}$, and $\mathrm{TCZ}$ were $38 \%, 63 \%$, and $58 \%$, respectively (ABA versus TNFi, $p=0.017)$.

Conclusions. We found that the effectiveness and safety of TCZ were maximized in patients aged $<75$ years and that patients aged $\geq 65$ years were the most suited candidates for ABA therapy. The use of therapeutic strategies appropriate to each age group might improve the outcomes of bDMARD therapy for RA.

\section{Background}

Because the ratio of elderly people has markedly increased, therapeutic strategies in patients with elderly rheumatoid arthritis (RA) are emerging and important concerns to be addressed. Especially in Japan which is rapidly transitioning into a super-aged society, with approximately $30 \%$ in the country being at least 65 years of age [1]. Consequently, maintaining the psychosomatic health of people aged 65-74 years and encouraging them to participate in social activities are some important issues. A new definition of true elderly people as those aged $\geq 75$ years has been proposed [2]. In such a super-aged society, patients with RA are also increasingly becoming older. Thus, Japan may be a good model for developing therapeutic strategies against RA in a super-aged society that the world will face in the future.

For RA, methotrexate (MTX) and biological disease-modifying antirheumatic drugs (bDMARDs) are key options for achieving treat-to-target goals [3]. This stands true for treating elderly RA patients. However, because elderly patients exhibit age-related decreases in activities of daily living (ADL) and organ function, the incidence of adverse events (AEs) increases inevitably [4]. Accordingly, conventional synthetic DMARDs (csDMARDs) are typically restricted for use. Conversely, because bDMARDs are less likely to be affected by renal and hepatic disorders, appropriate use of bDMARDs for treating RA may be more important in elderly patients than in young patients. Thus, the optimal therapeutic strategy using bDMARDs for elderly and young RA patients must be reexamined. Thus, the effectiveness and safety of bDMARDs should be compared and analyzed across age groups.

Drug retention rate reflects its effectiveness and safety [5]. In elderly patients, retention rates of individual bDMARDs and of bDMARDs by age group have been investigated [6-8]. Because frailty-an important risk factor for impaired $A D L$, hospitalization, and death-rapidly increases in elderly people aged $\geq 75$ years $[9,10]$, the effectiveness and safety of bDMARDs may differ even among the elderly such as between patients aged 65-74 years and those aged $\geq$ 
75 years. Therefore, the effectiveness and safety of bDMARDs by age group $(<65,65-74$, and $\geq 75$ years) should be compared and analyzed. However, there has been no comparative analysis of retention rates of bDMARDs among these age groups. Moreover, observational studies on retention rates of individual drugs have predominantly been conducted in actual clinical practice; as such selection bias represents a problem for comparisons between drugs.

In this study, selection bias was reduced by applying inverse probability of treatment weighting (IPTW) based on generalized propensity score $[11,12]$ and retention rates of bDMARDs were compared by age groups to clarify the optimal therapeutic strategies using bDMARDs.

\section{Methods}

Patients and study design. In total, 2,139 RA patients were treated with bDMARDs, including tumor necrosis factor inhibitors (TNFi) (infliximab [IFX], etanercept [ETN], adalimumab [ADA], golimumab [GLM], and certolizumab pegol [CZP]); abatacept (ABA); or tocilizumab (TCZ) between March 2003 and April 2017 at our institute and were retrospectively registered in our institute's observational registry (FIRST registry) (Additional file 1: Figure S1). Patients who received bDMARD therapy between February 2011 (MTX doses of up to $16 \mathrm{mg} /$ week were approved for adult RA in Japan) and April 2017, who were aged $\geq 20$ years, and who were followed up for at least 6 months were included in this study. Finally, 1,362 patients were enrolled, of which 695 were aged $<65$ years, 402 were aged $65-74$ years, and 265 were aged $\geq 75$ years. Patient data were retrospectively collected from the FIRST registry. RA was diagnosed based on the 1987 American College of Rheumatology Classification Criteria or 2010 American College of Rheumatology/European League against Rheumatism classification criteria [13-15]. The study was approved by the ethics review board of the university, and written informed consent was waived because of the retrospective study design.

bDMARD treatment. bDMARDs were prescribed to RA patients who were not adequately responsive to csDMARDs therapies. bDMARDs included both intravenous and subcutaneous agents and were administered based on the guidelines of the Japan College of Rheumatology.

Drug retention, discontinuation, and clinical effectiveness. The primary outcome was the drug retention rate in adjusted data analysis; secondary outcomes included reasons for discontinuation in non-adjusted data analysis and clinical effectiveness in non-adjusted and adjusted data analysis. Drug retention was analyzed according to the duration of treatment until drug discontinuation at the physician's judgment. Reasons for discontinuation were investigated using medical records and classified into discontinuation because of remission, effect insufficiency, AEs, or others (patient choice, economic, unspecified cause, and so on). Regarding discontinuation because of remission, physicians judged the state of the absence of disease activity based on composite measures such as the disease activity score using 28 joint counts (DAS28), the clinical disease activity index (CDAl), or the simple disease activity index $[16,17]$. Moreover, regarding effect insufficiency, physicians judged increase, return, or no change in disease activity based on composite measures. AEs were further classified according to Common Terminology Criteria for Adverse Events version 5.0 [18]. Because CDAI precisely reflects clinical response to bDMARDs, including TCZ [19], clinical effectiveness was evaluated as CDAI [20,21].

Statistical analysis. In analysis of baseline characteristics, summary statistics were presented using proportions for categorical data and medians and interquartile ranges for continuous data. In analysis of reasons for bDMARDs discontinuation, summary statistics were presented using of the number of incidents and incidence. Kruskal-Wallis and chi-square tests were used to assess differences among groups. In non-adjusted data analysis, the Kaplan-Meier method was used to assess drug retention rates. 
In adjusted data analysis, IPTW was used based on generalized propensity scores. Generally, covariate adjustments using propensity scores are performed for comparisons between two groups. For comparisons among multiple groups, the adjustment cannot be performed without any changes. The expanded concept of generalized propensity scores is applied to match multiple groups $[11,12]$. In this study, for covariate adjustment in the three groups of patients treated with TNFi, ABA, or TCZ, age, disease duration, gender, history of bDMARD use, MTX dose, glucocorticoid (GC) dose, tender joint count, swollen joint count, patient global assessment, evaluator global assessment, Health Assessment Questionnaire-Disability Index (HAQ-DI), C-reactive protein (CRP) level, erythrocyte sedimentation rate (ESR), and rheumatoid factor (RF) level were used as baseline covariates, and generalized propensity scores were estimated using multinomial logistic regression. Area under the curve of generalized propensity scores was $>0.7$ for each bDMARD. Balance following covariate adjustment was examined, and covariate adjustment was confirmed. bDMARD retention rates were analyzed using the Kaplan-Meier method and Cox proportional hazards model with adjustments using generalized propensity scores [12].

All reported $p$ values are two-sided, and the level of significance was $p<0.05$. All analyses were performed using JMP ${ }^{\circledR}$ version 13.0.0 (SAS Institute Inc., Cary, NC, USA), SPSS ${ }^{\circ}$ version 25 (SPSS Inc., Chicago, IL, USA), or STATA ${ }^{\circledR}$ version 14.0 (StataCorp, College Station, TX, USA).

\section{Results}

Retention rates of bDMARDs in non-adjusted data. Table 1 summarizes characteristics of all patients and age groups. Patients aged $\geq 75$ years exhibited higher incidence of advanced-stage RA, higher ABA and GC usage, higher preexisting lung disease prevalence, lower MTX usage, stronger inflammatory responses (e.g., CRP and ESR), higher RF levels, higher CDAI scores, and higher HAQ-DI scores than patients aged $<65$ and $65-74$ years.

Table 2 presents patient characteristics according to bDMARD usage. Additional file 1: Tables S1-3 present characteristics of each age group according to bDMARD usage. TNFi and TCZ usage decreased with age, whereas ABA usage remained comparable across age groups. TNFi-treated patients exhibited shorter disease duration, higher proportions of patients with Steinbrocker's stage I and II RA and biologics-naïve patients, higher MTX usage, and lower pre-existing lung disease prevalence than ABA- and TCZ-treated patients. ABA-treated patients showed longer disease duration, higher proportion of patients with Steinbrocker's stage III and IV RA, and higher pre-existing lung disease prevalence than those treated with other bDMARDs. TCZ-treated exhibited lower MTX usage, higher GC usage, higher CRP and ESR levels, and higher CDAl scores than those treated with other bDMARDs.

Three-year retention rates of bDMARDs in all patients and by age group are shown in Additional file 1: Figure S2 and Fig. 1. No significance test was performed because the data were non-adjusted. The three-year retention rate of bDMARDs was $48.9 \%$ in all patients (Additional file 1: Figure S2A), $48.6 \%$ in patients aged $<65$ years, $48.9 \%$ in patients aged $65-74$ years, and $50.6 \%$ in patients aged $\geq 75$ years (Additional file 1: Figure S2B). Three-year retention rates of TNFi, ABA, and TCZ were 42.6\%, 55.4\%, and 64.8\%, respectively, in all patients (Fig. 1A). Three-year retention rates in patients aged $<65,65-74$, and $\geq 75$ years were $43.1 \%, 43.2 \%$, and $39.7 \%$, respectively, for TNFi; $52.5 \%, 54.0 \%$, and $62.9 \%$, respectively, for ABA; and 67.0\%, 63.9\%, and 58.1\%, respectively, for TCZ (Fig. 1B, 1C, and 1D).

Risk factors for bDMARD discontinuation in non-adjusted data. In all patients, the risk factors for drug discontinuation included age (hazard ratio $[\mathrm{HR}]=0.992,95 \%$ confidence interval $[\mathrm{Cl}]=0.986-0.999)$, female gender $(\mathrm{HR}=0.672,95 \%$ $\mathrm{Cl}=0.554-0.821)$, HAQ-DI $(\mathrm{HR}=1.135,95 \% \mathrm{Cl}=1.013-1.272)$, TNFi versus $\mathrm{ABA}$ usage $(\mathrm{HR}=1.301,95 \% \mathrm{Cl}=1.065-$ 1.600), TNFi versus TCZ usage $(H R=1.919,95 \% \mathrm{Cl}=1.475-2.542)$, and $A B A$ versus $T C Z$ usage $(H R=1.474,95 \% \mathrm{Cl}=$ 1.085-2.024) (Additional file 1: Table S4). In patients aged $<65$ years, the risk factors for drug discontinuation were 
age $(\mathrm{HR}=0.988,95 \% \mathrm{Cl}=0.978-0.998)$ and TNFi versus TCZ usage $(\mathrm{HR}=1.825,95 \% \mathrm{Cl}=1.289-2.667)$ (Additional file 1: Table S5). In patients aged 65-74 years, the risk factors for drug discontinuation included age $(\mathrm{HR}=0.927,95 \%$ $\mathrm{Cl}=0.880-0.978)$, female gender $(\mathrm{HR}=0.524,95 \% \mathrm{Cl}=0.372-0.752)$, biologics-naïve patients $(\mathrm{HR}=0.653,95 \% \mathrm{Cl}=$ 0.471-0.914), and TNFi versus TCZ usage ( $\mathrm{HR}=2.128,95 \% \mathrm{Cl}=1.316-3.673)$ (Additional file 1: Table S6). In patients aged $\geq 75$ years, the risk factors for drug discontinuation were female gender $(\mathrm{HR}=0.520,95 \% \mathrm{Cl}=0.340-$ $0.820)$, $M T X$ usage $(\mathrm{HR}=0.435,95 \% \mathrm{Cl}=0.286-0.668), \mathrm{GC}$ usage $(\mathrm{HR}=2.085,95 \% \mathrm{Cl}=1.363-3.141)$, TNFi versus ABA usage $(\mathrm{HR}=2.036,95 \% \mathrm{Cl}=1.332-3.155)$, and $\mathrm{TNFi}$ versus $\mathrm{TCZ}$ usage $(\mathrm{HR}=2.220,95 \% \mathrm{Cl}=1.137-4.871)$ (Additional file 1: Table S7). bDMARD usage itself was a common risk factor for discontinuation in all age groups.

Retention rates of bDMARDs in adjusted data. Although non-adjusted data analyses suggested great differences in drug retention rates across bDMARD type, the retention rates were affected by patient selection bias. Thus, patient selection bias was minimized by applying IPTW based on generalized propensity score, and the retention rate of each bDMARD was compared among the age groups (Fig. 2). Differences in baseline characteristics were adjusted by IPTW (Additional file 1: Table S8). In all patients, three-year retention rates of TNFi, ABA, and TCZ were $43 \%, 51 \%$, and $65 \%$, respectively. The retention rate of TCZ was significantly higher than rates of ABA and TNFi (ABA versus TCZ, $p=$ 0.021 ; TNFi versus TCZ, $p<0.001$; Fig. $2 A$ ). In patients aged $<65$ years, three-year retention rates of TNFi, ABA, and TCZ were $43 \%, 47 \%$, and $69 \%$, respectively. The retention rate of TCZ was significantly higher than rates of ABA and TNFi (ABA versus TCZ, $p=0.017$; TNFi versus TCZ, $p=0.002$; Fig. 2B). In patients aged 65-74 years, three-year retention rates of $\mathrm{TNFi}, \mathrm{ABA}$, and $\mathrm{TCZ}$ were $44 \%, 53 \%$, and $60 \%$, respectively. The retention rate of $\mathrm{TCZ}$ was significantly higher than that for TNFi ( $p=0.034$; Fig. $2 \mathrm{C}$ ). In patients aged $\geq 75$ years, three-year retention rates for TNFi, ABA, and TCZ were $38 \%, 63 \%$, and $58 \%$, respectively. The retention rate of ABA was significantly higher than that of TNFi ( $p=0.017$; Fig. 2D). No statistical analysis was performed for TCZ usage data because of the small sample size. Overall, retention rates of TCZ were higher in patients aged $<65$ and $65-74$ years, and retention rates of ABA increased with age.

Reasons for bDMARD discontinuation in non-adjusted data. Reasons for the discontinuation of each bDMARD were analyzed by age (Table 3 and Additional file 1: Table S9). In patients aged < 65 years, discontinuation because of remission was more frequent following treatment with TNFi (16.9\%) and less frequent following treatment with TCZ (3.4\%). The prevalence of effect insufficiency was higher following treatment with ABA (22.0\%) and comparable between treatments with TNFi (14.5\%) and TCZ (15.5\%). AE incidence was lower following treatment with ABA (4.9\%). Particularly, there was no incidence of skin and subcutaneous tissue disorders. Similarly, in patients aged 65-74 years, discontinuation because of remission was more frequent following treatment with TNFi (10.5\%) and the prevalence of effect insufficiency was lower following treatment with TCZ (8.5\%). AE incidence was comparable among the three drugs. Likewise, in patients aged $\geq 75$ years, discontinuation because of remission was more frequent following treatment with TNFi (9.9\%). The prevalence of effect insufficiency was comparable among the three drugs, and $A E$ incidence was lower following treatment with TCZ (6.9\%) and ABA (4.3\%). Among AEs, the incidence of infections was lower following treatment with $A B A$. Overall, the rate of discontinuation because of remission was higher following treatment with TNFi and $A E$ incidence was lower following treatment with $A B A$ in all age groups.

\section{Retention rate of each bDMARD in adjusted data after excluding patients who discontinued treatment because of}

remission. Among the reasons for bDMARD discontinuation, the rate of discontinuation because of remission was higher following treatment with TNFi in each age group. Thus, patients who discontinued treatment because of remission were excluded from the analysis. The background characteristics of the remaining patients according to age and bDMARD usage are presented in Additional file 1: Tables S10-13. Retention rates were analyzed (Additional file 1: Figure S3) after adjusting for differences in baseline characteristics using IPTW (Additional file 1: Table S14). In 
all patients, three-year retention rates of TNFi, ABA, and TCZ were 48\%, 55\%, and $69 \%$, respectively. The retention rate of TCZ was significantly higher than rates of ABA and TNFi (ABA versus TCZ, $p=0.029$; TNFi versus TCZ, $p=0.001$; Additional file 1: Figure S3A). In patients aged $<65$ years, three-year retention rates of TNFi, ABA, and TCZ were $52 \%$, $52 \%$, and $73 \%$, respectively. The retention rate of TCZ was significantly higher than rates for ABA and TNFi (ABA versus TCZ, $p=0.025$; TNFi versus TCZ, $p=0.011$; Additional file 1: Figure S3B). In patients aged 65-74 years, threeyear retention rates of TNFi, $\mathrm{ABA}$, and TCZ were $48 \%, 55 \%$, and $63 \%$, respectively. The retention rate of TCZ was significantly higher than that of TNFi ( $p=0.048$; Additional file 1: Figure S3C). In patients aged $\geq 75$ years, three-year retention rates of $\mathrm{TNFi}, \mathrm{ABA}$, and $\mathrm{TCZ}$ were $42 \%, 65 \%$, and $63 \%$, respectively. The retention rate of $\mathrm{ABA}$ was significantly higher than that of TNFi ( $p=0.019$; Additional file 1: Figure S3D). No statistical analysis was performed for TCZ data because of the small sample size. Overall, similar results to those shown in Fig. 2 were obtained even after patients who discontinued treatment because of remission were excluded.

Changes in disease activity in non-adjusted and adjusted data. Changes in CDAI were analyzed to evaluate the effects of bDMARDs. First, non-adjusted data analysis was performed to analyze CDAl at baseline and 1, 2, and 3 years (Additional file 1: Figure S4). In all patients and in each age group, CDAl tended to change in a similar manner among patients treated with TNFi, ABA, and TCZ (Additional file 1: Figure S4A, B, C, and D). Disease activity remained low in many patients who continued treatment, regardless of the bDMARD type. Furthermore, changes in CDAI from baseline to 1, 2, and 3 years were analyzed using IPTW based on generalized propensity scores (Fig. 3). In all patients, the greatest improvement in CDAI was observed with TNFi treatment, with mean differences of $-12.2(95 \% \mathrm{Cl}=-13.5$ to $-10.9)$ at $1,-12.3(95 \% \mathrm{Cl}=-14.2$ to -10.5$)$ at 2 , and $-13.6(95 \% \mathrm{Cl}=-15.9$ to -11.2$)$ at 3 years (Fig. 3A). Patients aged $<65$ years showed the greatest improvement in CDAl following TNFi treatment, with a mean difference of -12.9 $(95 \% \mathrm{Cl}=-14.5$ to -11.3 ) at 1 year (Fig. 3B). Conversely, in the remaining age groups, there were no significant differences in the degree of CDAl improvement following TNFi, ABA, or TCZ treatment (Fig. 3C and D). In patients aged 65-74 and $\geq 75$ years (Fig. $3 \mathrm{C}$ and D), differences in CDAl at 1 year were $-11.5(95 \% \mathrm{Cl}=-14.0$ to -9.0$)$ and -11.6 $(95 \% \mathrm{Cl}=-15.5$ to -7.7$)$, respectively, for $\mathrm{TNFi},-4.7(95 \% \mathrm{Cl}:-9.7$ to 0.2$)$ and $-6.4(95 \% \mathrm{Cl}=-10.9$ to -2.0$)$, respectively, for $\mathrm{ABA}$, and $-3.1(95 \% \mathrm{Cl}=-8.9$ to 2.6$)$ and $-3.8(95 \% \mathrm{Cl}=-14.6$ to 6.9$)$, respectively, for TCZ. For TCZ, because of the small sample size, the $95 \%$ Cls for changes in CDAl at 2 and 3 years were wide, particularly in the older age groups, and the results for this drug should only be used as a reference.

\section{Discussion}

In this study, after reducing selection bias by applying IPTW based on generalized propensity score, the long-term retention rates of bDMARDs were examined by age group in actual clinical practice. Consequently, the following two novel points were revealed. First, in all age groups, the highest retention rate was observed for TCZ. Second, in patients aged at least 65 years, the retention rates of ABA and TCZ were similar. Moreover, secondary assessment revealed the following two points. First, in all age groups, the lowest rate of discontinuation because of AEs was observed with ABA. Second, TNFi treatment improved disease activity more effectively and was associated with the highest rate of discontinuation because of clinical remission in all age groups.

In this study, the retention rate of TCZ was high in all age groups, particularly in patients aged $<65$ years, and remained high in those aged $\geq 65$ years. In a meta-analysis of studies on RA, TCZ and MTX combination was identified as the best intervention [22]. TCZ showed higher retention rates than TNFi and ABA in other studies [23, 24], which supports the results of this study. The retention rates of ABA and TCZ were similar in patients aged $\geq 65$ years, and this similarity more pronounced in those aged $\geq 75$ years. As a possible explanation for these findings, it is important that $A B A$ showed the lowest discontinuation rate because of AEs in all age groups in this study and that the degree of improvement in disease activity was comparable among the drugs in patients aged $\geq 75$ years. Regarding 
safety and age, an all-case postmarketing surveillance of bDMARDs in Japan revealed that age ( $\geq 65$ years) contributed to severe infection onset with all biopharmaceuticals except for $A B A$ [25-28]. Long-term safety of $A B A$ $[29,30]$ has been reported, and guidelines of the British Society for Rheumatology recommend ABA as the first-line treatment for patients at a risk of infection [31]. The efficacy of ABA is similar to that of TNFi [32, 33] and TCZ [34].

Elderly RA patients often present higher disease activity and greater functional impairment than young patients [35]. In recent years, immunosenescence has attracted much attention, and risk of inflammation and autoimmune diseases increases with age [36]. Immunosenescence is characterized by the lack of CD28 in T-cells [36], and CD28-negative Tcell count increases with age [37]. Lack of CD28 in CD4-positive T-cells is associated with chronic autoimmune diseases, including RA [36]. ABA therapy reduces CD28-negative CD4-positive T-cell counts, and this reduction in CD28-negative T-cell count is associated with the responsiveness of RA as assessed by DAS28 based on CRP level $[38,39]$. Thus, ABA may be suitable for improving immune dysregulation in elderly RA patients. However, previous studies at our institution as well as others reported that high CD28-negative CD4-positive T-cell count increases the risk of decreased responsiveness to ABA therapy [40], and the responsiveness to ABA therapy improves with decreasing pretreatment CD28-negative T-cell count [41]. That is, some elderly people may be at a risk of acquiring treatment resistance because of increasing CD28-negative T-cell count with increasing age. These previous studies suggest that heterogeneity increases in elderly RA patients. Thus, drug selection based on both safety and treatment responsiveness is preferable.

In terms of disease activity, non-adjusted data analysis demonstrated that the degree of improvement was comparable among the three bDMARDs, although adjusted data analysis identified differences in the degree of improvement among TNFi, ABA, and TCZ. These differences suggested that patient selection bias, as indicated by differences in patient characteristics in the non-adjusted data, maximized the effect of each bDMARD in actual clinical practice. In adjusted data analysis, the improvement achieved with TNFi was greater in all age groups, and this effect was especially pronounced in patients aged < 65 years. The Remission Induction by Remicade in RA (RRR) study using IFX at our institution [42], the Humira Discontinuation without Functional and Radiographic Damage Progression following Sustained Remission (HONOR) study using ADA at our institution [43, 44], and other studies [45-47] reported that TNFi therapy may lead to discontinuation because of remission. Early-stage RA was also identified as highly reliable predictors of successful bDMARD tapering [3]. Although TNFi showed the lowest retention rate among the three bDMARDs groups, future studies are warranted to reveal characteristics of patient populations in which TNFi use is preferred and can achieve discontinuation because of remission.

This study has some limitations. First, the data were obtained from routine clinical practice, and no clear criteria were set for bDMARD discontinuation, with the decision being left at the attending physician's discretion. Second, because IPTW based on generalized propensity score cannot exclude the effects of unknown confounding factors, this study may not have sufficiently eliminated biases compared with randomized controlled trials. Third, because IFX, ETN, ADA, GLM, and CZP were analyzed collectively as TNFi, the characteristics of each TNFi may not have been reflected.

Fourth, the sample size of patients treated with TCZ was small; thus, the retention rate of TCZ among patients aged $\geq$ 75 years and changes in CDAl at 2 and 3 years with TCZ therapy in patients aged 65-74 and $\geq 75$ years could only be used as a reference. Finally, this study did not include any Janus kinase inhibitors, the use of which will increase in the future.

\section{Conclusions}

Despite the aforementioned limitations, this study found that the effectiveness and safety of TCZ were maximized in patients aged $<75$ years and that patients aged at least 65 years (particularly those aged $\geq 75$ years) were the most 
suited candidates for ABA therapy. Furthermore, in patients aged $<65$ years, TNFi improved disease activity more

effectively and was associated with increased frequently of discontinuation because of remission. Finally, the use of therapeutic strategies appropriate to each age group might improve the outcomes of bDMARD therapy for RA.

\section{Abbreviations}

RA

Rheumatoid arthritis

MTX

Methotrexate

bDMARDs

Biological disease-modifying antirheumatic drugs

ADL

Activities of daily living

AEs

Adverse events

csDMARDs

Conventional synthetic disease-modifying antirheumatic drugs

IPTW

Inverse probability of treatment weighting

$\mathrm{TNFi}$

Tumor necrosis factor inhibitors

IFX

Infliximab

ETN

Etanercept

ADA

Adalimumab

GLM

Golimumab

CZP

Certolizumab pegol

ABA

Abatacept

TCZ

Tocilizumab

DAS28

Disease activity score using 28 joint counts

CDAI

Clinical disease activity index

GC

Glucocorticoid

HAQ-DI

Health Assessment Questionnaire-Disability Index

CRP 
C-reactive protein

ESR

Erythrocyte sedimentation rate

RF

Rheumatoid factor

HR

Hazard ratio

$\mathrm{Cl}$

Confidence interval

\section{Declarations}

Ethics approval and consent to participate. This study was approved by the ethics review board of the University of Occupational and Environmental Health, Japan, and written informed consent was waived because of the retrospective study design.

Consent for publication. Not applicable.

Availability of data and materials. The datasets used and/or analyzed during the current study are available from the corresponding author on reasonable request.

Competing interests. AK has received speaking fees and/or honoraria from Bristol-Myers and Janssen (less than $\$ 10,000$ each). KN has received speaking fees and/or honoraria from Bristol-Myers, Sanofi, AbbVie, Eisai, Eli Lilly, Chugai, Pfizer, Takeda, and Mitsubishi-Tanabe (less than $\$ 10,000$ each), and research grants from Mitsubishi-Tanabe and Eisai. SK has received speaking fees and/or honoraria from Eli Lilly, Bristol-Myers, Pfizer, and Takeda (less than $\$ 10,000$ each). TA declare no conflict of interest. YT has received speaking fees and/or honoraria from DaiichiSankyo, Astellas, Pfizer, Mitsubishi-Tanabe, Bristol-Myers, Chugai, Eli Lilly, Abbvie (more than \$10,000 each), UCB, YL Biologics, Takeda, Eisai, Novartis, Janssen, and Teijin (less than \$10,000 each), and research grants from Asahi-kasei, Mitsubishi-Tanabe, Chugai, Takeda, Sanofi, Bristol-Myers, UCB, Daiichi-Sankyo, Eisai, and Ono.

Funding. This research received no specific grant from any funding agency in the public, commercial, or not-for-profit sectors.

Authors' contributions. AK, KN, and YT contributed to the study conception and design. AK, KN, SK, and YT contributed to the acquisition of data. AK, KN, SK, TA, and YT contributed to the analysis and interpretation of data. All authors drafted the article or revising it critically for important intellectual content and approved of the final version of the article to be published.

Acknowledgements. The authors thank all the medical staff at our institution for providing the data. We also thank Yoshihisa Fujino, MD, PhD, MPH (Institute of Industrial Ecological Sciences, University of Occupational and Environmental Health, Japan) for valuable comments to this work.

\section{References}

1. Statistics Bureau, Ministry of Internal Affairs and Communications Japan: Statistical Handbook of Japan 2018. https://www.stat.go.jp/english/data/handbook/pdf/2018all.pdf. Accessed 7 Nov 2018. 
2. Ouchi Y, Rakugi H, Arai H, Akishita M, Ito H, Toba K, et al. Redefining the elderly as aged 75 years and older: Proposal from the Joint Committee of Japan Gerontological Society and the Japan Geriatrics Society. Geriatrics \& gerontology international. 2017;17(7):1045-7.

3. Smolen JS, Landewe R, Bijlsma J, Burmester G, Chatzidionysiou K, Dougados M, et al. EULAR recommendations for the management of rheumatoid arthritis with synthetic and biological disease-modifying antirheumatic drugs: 2016 update. Annals of the rheumatic diseases. 2017;76(6):960-77.

4. Rothschild JM, Bates DW, Leape LL. Preventable medical injuries in older patients. Archives of internal medicine. 2000;160(18):2717-28.

5. Neovius M, Arkema EV, Olsson H, Eriksson JK, Kristensen LE, Simard JF, et al. Drug survival on TNF inhibitors in patients with rheumatoid arthritis comparison of adalimumab, etanercept and infliximab. Annals of the rheumatic diseases. 2015;74(2):354-60.

6. Pers YM, Schaub R, Constant E, Lambert J, Godfrin-Valnet M, Fortunet C, et al. Efficacy and safety of tocilizumab in elderly patients with rheumatoid arthritis. Joint, bone, spine : revue du rhumatisme. 2015;82(1):25-30.

7. Cho SK, Sung YK, Kim D, Won S, Choi CB, Kim TH, et al. Drug retention and safety of TNF inhibitors in elderly patients with rheumatoid arthritis. BMC musculoskeletal disorders. 2016;17:333.

8. Filippini M, Bazzani C, Favalli EG, Marchesoni A, Atzeni F, Sarzi-Puttini P, et al. Efficacy and safety of anti-tumour necrosis factor in elderly patients with rheumatoid arthritis: an observational study. Clinical reviews in allergy \& immunology. 2010;38(2-3):90-6.

9. Fried LP, Tangen CM, Walston J, Newman AB, Hirsch C, Gottdiener J, et al. Frailty in older adults: evidence for a phenotype. The journals of gerontology Series A, Biological sciences and medical sciences. 2001;56(3):M146-56.

10. Shimada H, Makizako H, Doi T, Yoshida D, Tsutsumimoto K, Anan Y, et al. Combined prevalence of frailty and mild cognitive impairment in a population of elderly Japanese people. Journal of the American Medical Directors Association. 2013;14(7):518-24.

11. Imbens GW. The role of the propensity score in estimating dose-response functions. Biometrika. 2000;87(3):70610.

12. Sugihara M. Survival analysis using inverse probability of treatment weighted methods based on the generalized propensity score. Pharmaceutical statistics. 2010;9(1):21-34.

13. Arnett FC, Edworthy SM, Bloch DA, McShane DJ, Fries JF, Cooper NS, et al. The American Rheumatism Association 1987 revised criteria for the classification of rheumatoid arthritis. Arthritis and rheumatism. 1988;31(3):315-24.

14. Aletaha D, Neogi T, Silman AJ, Funovits J, Felson DT, Bingham CO, 3rd, et al. 2010 Rheumatoid arthritis classification criteria: an American College of Rheumatology/European League Against Rheumatism collaborative initiative. Arthritis and rheumatism. 2010;62(9):2569-81.

15. Aletaha D, Neogi T, Silman AJ, Funovits J, Felson DT, Bingham CO, 3rd, et al. 2010 rheumatoid arthritis classification criteria: an American College of Rheumatology/European League Against Rheumatism collaborative initiative. Annals of the rheumatic diseases. 2010;69(9):1580-8.

16. Anderson J, Caplan L, Yazdany J, Robbins ML, Neogi T, Michaud K, et al. Rheumatoid arthritis disease activity measures: American College of Rheumatology recommendations for use in clinical practice. Arthritis care \& research. 2012;64(5):640-7.

17. Inoue E, Yamanaka H, Hara M, Tomatsu T, Kamatani N. Comparison of Disease Activity Score (DAS)28erythrocyte sedimentation rate and DAS28- C-reactive protein threshold values. Annals of the rheumatic diseases. 2007;66(3):407-9.

Page $10 / 18$ 
18. US Department of Health and Human Services: Common Terminology Criteria for Adverse Events (CTCAE) Version 5.0.

https://ctep.cancer.gov/protocolDevelopment/electronic_applications/docs/CTCAE_v5_Quick_Reference_5x7.pdf. Accessed 15 Sept 2019.

19. Funahashi K, Koyano S, Miura T, Hagiwara T, Okuda K, Matsubara T. Efficacy of tocilizumab and evaluation of clinical remission as determined by CDAl and MMP-3 level. Modern rheumatology. 2009;19(5):507-12.

20. Aletaha D, Nell VP, Stamm T, Uffmann M, Pflugbeil S, Machold K, et al. Acute phase reactants add little to composite disease activity indices for rheumatoid arthritis: validation of a clinical activity score. Arthritis research \& therapy. 2005;7(4):R796-806.

21. Aletaha D, Smolen J. The Simplified Disease Activity Index (SDAI) and the Clinical Disease Activity Index (CDAI): a review of their usefulness and validity in rheumatoid arthritis. Clinical and experimental rheumatology. 2005;23(5 Suppl 39):S100-8.

22. Cai W, Gu Y, Cui H, Cao Y, Wang X, Yao Y, et al. The Efficacy and Safety of Mainstream Medications for Patients With cDMARD-Naive Rheumatoid Arthritis: A Network Meta-Analysis. Frontiers in pharmacology. 2018;9:138.

23. Lauper K, Nordstrom DC, Pavelka K, Hernandez MV, Kvien TK, Kristianslund EK, et al. Comparative effectiveness of tocilizumab versus TNF inhibitors as monotherapy or in combination with conventional synthetic diseasemodifying antirheumatic drugs in patients with rheumatoid arthritis after the use of at least one biologic diseasemodifying antirheumatic drug: analyses from the pan-European TOCERRA register collaboration. Annals of the rheumatic diseases. 2018;77(9):1276-82.

24. Gottenberg JE, Morel J, Perrodeau E, Bardin T, Combe B, Dougados M, et al. Comparative effectiveness of rituximab, abatacept, and tocilizumab in adults with rheumatoid arthritis and inadequate response to TNF inhibitors: prospective cohort study. BMJ (Clinical research ed). 2019;364:167.

25. Takeuchi T, Tatsuki Y, Nogami Y, Ishiguro N, Tanaka Y, Yamanaka H, et al. Postmarketing surveillance of the safety profile of infliximab in 5000 Japanese patients with rheumatoid arthritis. Annals of the rheumatic diseases. 2008;67(2):189-94.

26. Koike T, Harigai M, Inokuma S, Ishiguro N, Ryu J, Takeuchi T, et al. Postmarketing surveillance of safety and effectiveness of etanercept in Japanese patients with rheumatoid arthritis. Modern rheumatology. 2011;21(4):343-51.

27. Koike T, Harigai M, Ishiguro N, Inokuma S, Takei S, Takeuchi T, et al. Safety and effectiveness of adalimumab in Japanese rheumatoid arthritis patients: postmarketing surveillance report of 7740 patients. Modern rheumatology. 2014;24(3):390-8.

28. Koike T, Harigai M, Inokuma S, Ishiguro N, Ryu J, Takeuchi T, et al. Effectiveness and safety of tocilizumab: postmarketing surveillance of 7901 patients with rheumatoid arthritis in Japan. The Journal of rheumatology. 2014;41(1):15-23.

29. Alten R, Kaine J, Keystone E, Nash P, Delaet I, Genovese MC. Long-term safety of subcutaneous abatacept in rheumatoid arthritis: integrated analysis of clinical trial data representing more than four years of treatment. Arthritis \& rheumatology (Hoboken, NJ). 2014;66(8):1987-97.

30. Genovese MC, Schiff M, Luggen M, Le Bars M, Aranda R, Elegbe A, et al. Longterm safety and efficacy of abatacept through 5 years of treatment in patients with rheumatoid arthritis and an inadequate response to tumor necrosis factor inhibitor therapy. The Journal of rheumatology. 2012;39(8):1546-54.

31. Holroyd CR, Seth R, Bukhari M, Malaviya A, Holmes C, Curtis E, et al. The British Society for Rheumatology biologic DMARD safety guidelines in inflammatory arthritis. Rheumatology (Oxford). 2018. 
32. Schiff M, Weinblatt ME, Valente R, van der Heijde D, Citera G, Elegbe A, et al. Head-to-head comparison of subcutaneous abatacept versus adalimumab for rheumatoid arthritis: two-year efficacy and safety findings from AMPLE trial. Annals of the rheumatic diseases. 2014;73(1):86-94.

33. Kubo S, Nakayamada S, Nakano K, Sawamukai N, Hirata S, Hanami K, et al. Comparison of efficacy of TNF inhibitors and abatacept in patients with rheumatoid arthritis; Adjusted with propensity score matching. Clinical immunology (Orlando, Fla). 2018;191:67-74.

34. Kubo S, Nakayamada S, Nakano K, Hirata S, Fukuyo S, Miyagawa I, et al. Comparison of the efficacies of abatacept and tocilizumab in patients with rheumatoid arthritis by propensity score matching. Annals of the rheumatic diseases. 2016;75(7):1321-7.

35. Ishchenko A, Lories RJ. Safety and Efficacy of Biological Disease-Modifying Antirheumatic Drugs in Older Rheumatoid Arthritis Patients: Staying the Distance. Drugs \& aging. 2016;33(6):387-98.

36. Boots AM, Maier AB, Stinissen P, Masson P, Lories RJ, De Keyser F. The influence of ageing on the development and management of rheumatoid arthritis. Nature reviews Rheumatology. 2013;9(10):604-13.

37. Fagnoni FF, Vescovini R, Mazzola M, Bologna G, Nigro E, Lavagetto G, et al. Expansion of cytotoxic CD8+ CD28- T cells in healthy ageing people, including centenarians. Immunology. 1996;88(4):501-7.

38. Imberti L, Scarsi M, Zanotti C, Chiarini M, Bertoli D, Tincani A, et al. Reduced T-cell repertoire restrictions in abatacept-treated rheumatoid arthritis patients. Journal of translational medicine. 2015;13:12.

39. Scarsi M, Ziglioli T, Airo P. Decreased circulating CD28-negative T cells in patients with rheumatoid arthritis treated with abatacept are correlated with clinical response. The Journal of rheumatology. 2010;37(5):911-6.

40. Fukuyo S, Nakayamada S, Iwata S, Kubo S, Saito K, Tanaka Y. Abatacept therapy reduces CD28+CXCR5+ follicular helper-like T cells in patients with rheumatoid arthritis. Clinical and experimental rheumatology. 2017;35(4):562-70.

41. Scarsi M, Ziglioli T, Airo P. Baseline numbers of circulating CD28-negative T cells may predict clinical response to abatacept in patients with rheumatoid arthritis. The Journal of rheumatology. 2011;38(10):2105-11.

42. Tanaka Y, Takeuchi T, Mimori T, Saito K, Nawata M, Kameda H, et al. Discontinuation of infliximab after attaining low disease activity in patients with rheumatoid arthritis: RRR (remission induction by Remicade in RA) study. Annals of the rheumatic diseases. 2010;69(7):1286-91.

43. Hirata S, Saito K, Kubo S, Fukuyo S, Mizuno Y, Iwata S, et al. Discontinuation of adalimumab after attaining disease activity score 28-erythrocyte sedimentation rate remission in patients with rheumatoid arthritis (HONOR study): an observational study. Arthritis research \& therapy. 2013;15(5):R135.

44. Tanaka Y, Hirata S, Kubo S, Fukuyo S, Hanami K, Sawamukai N, et al. Discontinuation of adalimumab after achieving remission in patients with established rheumatoid arthritis: 1-year outcome of the HONOR study. Annals of the rheumatic diseases. 2015;74(2):389-95.

45. Tanaka Y, Yamanaka H, Ishiguro N, Miyasaka N, Kawana K, Hiramatsu K, et al. Adalimumab discontinuation in patients with early rheumatoid arthritis who were initially treated with methotrexate alone or in combination with adalimumab: 1 year outcomes of the HOPEFUL-2 study. RMD open. 2016;2(1):e000189.

46. Atsumi T, Tanaka Y, Yamamoto K, Takeuchi T, Yamanaka H, Ishiguro N, et al. Clinical benefit of 1-year certolizumab pegol (CZP) add-on therapy to methotrexate treatment in patients with early rheumatoid arthritis was observed following CZP discontinuation: 2-year results of the C-OPERA study, a phase III randomised trial. Annals of the rheumatic diseases. 2017;76(8):1348-56.

47. Yamanaka H, Nagaoka S, Lee SK, Bae SC, Kasama T, Kobayashi H, et al. Discontinuation of etanercept after achievement of sustained remission in patients with rheumatoid arthritis who initially had moderate disease

Page $12 / 18$ 
activity-results from the ENCOURAGE study, a prospective, international, multicenter randomized study. Modern rheumatology. 2016;26(5):651-61.

\section{Tables}

Table 1. Baseline characteristics of the study population

\begin{tabular}{|c|c|c|c|c|c|}
\hline \multirow[b]{2}{*}{$\mathrm{N}$} & All patients & $<65 \mathrm{yr}$ & $65-74$ yr & $\geq 75 \mathrm{yr}$ & $p$ \\
\hline & 1,362 & 695 & 402 & 265 & \\
\hline Age (yr) & $64(54-72)$ & $54(44-60)$ & $69(67-72)$ & $79(76-81)$ & $<0.001$ \\
\hline Gender (female) (\%) & 81.6 & 83.3 & 79.4 & 80.4 & 0.227 \\
\hline Disease duration (yr) & $4(1-11)$ & $3(0.8-9)$ & $6(1.4-15)$ & $5(1.2-15)$ & $<0.001$ \\
\hline Stage (I + II) $(\%)$ & 68.2 & 76.0 & 61.7 & 57.8 & $<0.001$ \\
\hline TNFi/ABA/TCZ (\%) & $59.2 / 25.8 / 15.0$ & $65.6 / 17.7 / 16.7$ & $57 / 28.4 / 14.7$ & $45.7 / 43.4 / 10.9$ & $<0.001$ \\
\hline Bio-naïve (\%) & 74.1 & 75.4 & 71.9 & 74 & 0.442 \\
\hline MTX use (\%) & 77.8 & 85.3 & 72.9 & 65.3 & $<0.001$ \\
\hline MTX dose $(\mathrm{mg} / \mathrm{w})$ & $14(10-16)$ & $14(10-16)$ & $12(10-16)$ & $12(8-16)$ & $<0.001$ \\
\hline GC use (\%) & 21.2 & 17.3 & 24.4 & 26.8 & 0.001 \\
\hline GC dose $(\mathrm{mg} / \mathrm{d})$ & $5(2.5-7.5)$ & $4(2.5-5)$ & $5(2.5-9.3)$ & $5(2.5-7.5)$ & 0.157 \\
\hline $\mathrm{CRP}(\mathrm{mg} / \mathrm{dL})$ & $1.0(0.2-3.0)$ & $0.6(0.1-2.2)$ & $1.3(0.3-3.2)$ & $1.5(0.4-4.2)$ & $<0.001$ \\
\hline $\mathrm{ESR}(\mathrm{mm} / \mathrm{h})$ & $47(24-75)$ & $35(17-62)$ & $58(32-80)$ & $66(38-85)$ & $<0.001$ \\
\hline $\mathrm{RF}(\mathrm{IU} / \mathrm{mL})$ & $60(18-167)$ & $45(14-130)$ & $67(23-188)$ & $105(28-215)$ & $<0.001$ \\
\hline ACPA positive (\%) & 73.3 & 70.1 & 77.1 & 75.8 & 0.026 \\
\hline TJC, 0-28 & $7(4-12)$ & $7(3-12)$ & $7(3-12)$ & $8(4-13)$ & 0.062 \\
\hline SJC, 0-28 & $6(3-10)$ & $6(3-9)$ & $6(3-10)$ & $7(4-11)$ & 0.001 \\
\hline PGA, 0-100 mm & $52(35-72)$ & $51(32-71)$ & $51(35-70)$ & $57(42-76)$ & 0.002 \\
\hline EGA, 0-100 mm & $43(29-58)$ & $40(26-55)$ & $43(30-57)$ & $49(34-62)$ & $<0.001$ \\
\hline CDAI & $24(16-32)$ & $23(15-31)$ & $24(16-34)$ & $27(20-35)$ & $<0.001$ \\
\hline HAQ-DI & $1.3(0.6-2.0)$ & $1(0.4-1.6)$ & $1.3(0.6-2)$ & $1.9(1.3-2.5)$ & $<0.001$ \\
\hline $\begin{array}{l}\text { Pre-existing lung disease } \\
\text { (\%) }\end{array}$ & 27.4 & 18.4 & 32.3 & 43.4 & $<0.001$ \\
\hline
\end{tabular}


Values are the median (interquartile range) unless indicated otherwise. $y r=$ years; $w=$ week; $d=$ day; Stage $=$ Steinbrocker's stages; $\mathrm{TNFi}=$ tumor necrosis factor inhibitors; $\mathrm{ABA}=$ abatacept; $\mathrm{TCZ}=$ tocilizumab; Bio-naïve = biologics-naïve patients; $\mathrm{MTX}=$ methotrexate; $\mathrm{GC}=$ glucocorticoid; $\mathrm{CRP}=\mathrm{C}$ reactive protein; $\mathrm{ESR}=$ erythrocyte sedimentation rate; $\mathrm{RF}=$ rheumatoid factor; $\mathrm{ACPA}=$ anticitrullinated peptide antibody; TJC = tender joint count; SJC = swollen joint count; PGA = patient global assessment visual analogue scale; EGA = evaluator global assessment visual analogue scale; $\mathrm{CDAI}=$ clinical disease activity index; HAQ-DI = health assessment questionnaire-disability index.

Table 2. Baseline characteristics of patients treated with bDMARDs 


\begin{tabular}{|c|c|c|c|c|}
\hline & $\mathrm{TNFi}$ & $\mathrm{ABA}$ & TCZ & $p$ \\
\hline $\mathrm{N}$ & 806 & 352 & 204 & \\
\hline Age (yr) & $62(51-71)$ & $68(60-76)$ & $63(54-70)$ & $<0.001$ \\
\hline$<65 / 65-74 / \geq 75$ yr (\%) & $56.6 / 28.4 / 15$ & $34.9 / 32.4 / 32.7$ & $56.9 / 28.9 / 14.2$ & $<0.001$ \\
\hline Gender (female) (\%) & 79.9 & 85.5 & 81.4 & 0.077 \\
\hline Disease duration (yr) & $3(0.8-9)$ & $7(2-16)$ & $5(1.3-12)$ & $<0.001$ \\
\hline Stage (I + II) (\%) & 74.1 & 56.3 & 65.7 & $<0.001$ \\
\hline Bio-naïve (\%) & 80.1 & 63.6 & 68.1 & $<0.001$ \\
\hline MTX use (\%) & 87.5 & 66.5 & 58.8 & $<0.001$ \\
\hline MTX dose (mg/w) & $14(10-16)$ & $12(8-16)$ & $12(8-16)$ & $<0.001$ \\
\hline GC use (\%) & 17.6 & 24.4 & 29.9 & $<0.001$ \\
\hline GC dose $(\mathrm{mg} / \mathrm{d})$ & $4.5(2.5-6.3)$ & $4.5(2.5-8)$ & $5(2.5-7.8)$ & 0.672 \\
\hline CRP (mg/dL) & $0.8(0.2-3)$ & $0.7(0.1-2)$ & $2.3(0.7-5.3)$ & $<0.001$ \\
\hline $\operatorname{ESR}(\mathrm{mm} / \mathrm{h})$ & $43(20-73)$ & $44(24-71)$ & $63(40-85)$ & $<0.001$ \\
\hline $\mathrm{RF}(\mathrm{IU} / \mathrm{mL})$ & $52(16-151)$ & $78(25-199)$ & $72(19-161)$ & 0.003 \\
\hline ACPA positive (\%) & 72.5 & 76.1 & 71.6 & 0.274 \\
\hline TJC, 0-28 & $7(4-12)$ & $6(3-12)$ & $8(4-13)$ & 0.008 \\
\hline SJC, 0-28 & $6(3-10)$ & $6(2-9)$ & $7(4-11)$ & 0.001 \\
\hline PGA, 0-100 (mm) & $52(35-71)$ & $50(33-71)$ & $55(38-75)$ & 0.168 \\
\hline EGA, 0-100 (mm) & $45(30-60)$ & $40(25-52)$ & $43(31-59)$ & 0.002 \\
\hline CDAI & $24(16-32)$ & $22(15-31)$ & $26(18-35)$ & 0.001 \\
\hline HAQ-DI & $1.1(0.5-1.9)$ & $1.4(0.6-2.1)$ & $1.4(0.8-2.1)$ & 0.004 \\
\hline Pre-existing lung disease (\%) & 22.5 & 39.8 & 25.5 & $<0.001$ \\
\hline
\end{tabular}

Values are the median (interquartile range) unless indicated otherwise. $y r=$ years; $w=$ week; $d=d a y$;

Stage $=$ Steinbrocker's stages; TNFi = tumor necrosis factor inhibitors; $\mathrm{ABA}=$ abatacept; $\mathrm{TCZ}=$ tocilizumab; Bio-naïve = biologics-naïve patients; MTX = methotrexate; GC = glucocorticoid; CRP = Creactive protein; $\mathrm{ESR}=$ erythrocyte sedimentation rate; $\mathrm{RF}=$ rheumatoid factor; $\mathrm{ACPA}=$ anticitrullinated peptide antibody; TJC = tender joint count; SJC = swollen joint count; PGA = patient 
global assessment visual analogue scale; EGA = evaluator global assessment visual analogue scale;

CDAI = clinical disease activity index; HAQ-DI = health assessment questionnaire-disability index.

Figures
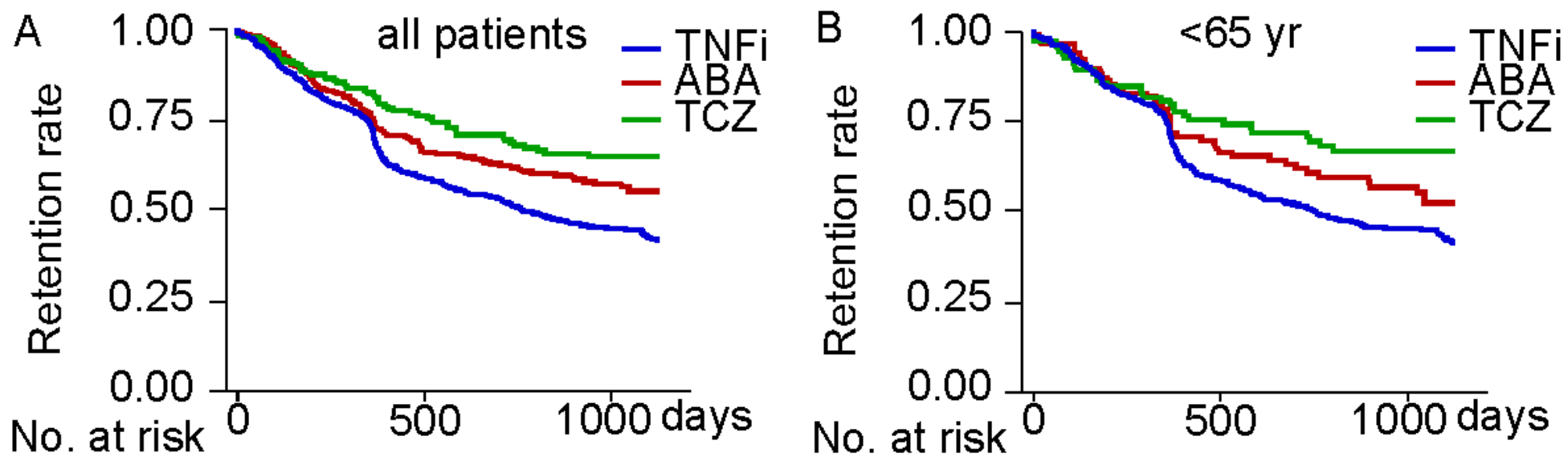

TNFi=806 $595 \quad 369262 \quad 187$ $A B A=352 \quad 255 \quad 167 \quad 116 \quad 82$ TCZ=204 $157 \quad 118 \quad 94 \quad 53$

TNFi=456 $350 \quad 207 \quad 145 \quad 107$ $\mathrm{ABA}=123 \quad 95 \quad 64 \quad 50 \quad 35$ TCZ=116 $90 \quad 67 \quad 57 \quad 35$
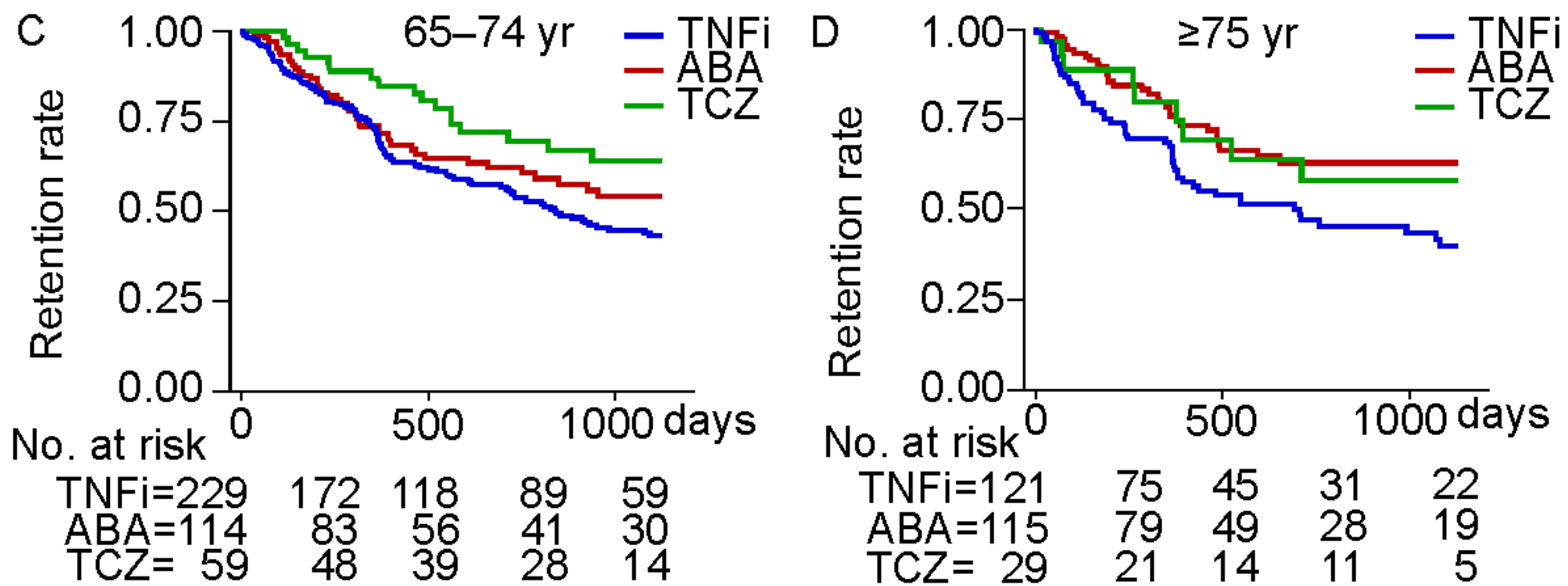
No. at risk

$\mathrm{TNFi}=121$

ABA $=115 \quad 79 \quad 49 \quad 28 \quad 19$ $\mathrm{TCZ}=29 \quad 21 \quad 14 \quad 11 \quad 5$

Figure 1

Three-year retention rates of bDMARDs by age group in non-adjusted data Three-year retention rates of bDMARDs in all patients $(A)$, in patients aged $<65$ years $(B)$, in patients aged $65-74$ years $(C)$, and in patients aged $\geq 75$ years (D). $y r=$ years; No. at risk = number at risk; TNFi = tumor necrosis factor inhibitors; $A B A=$ abatacept; $T C Z=$ tocilizumab. 

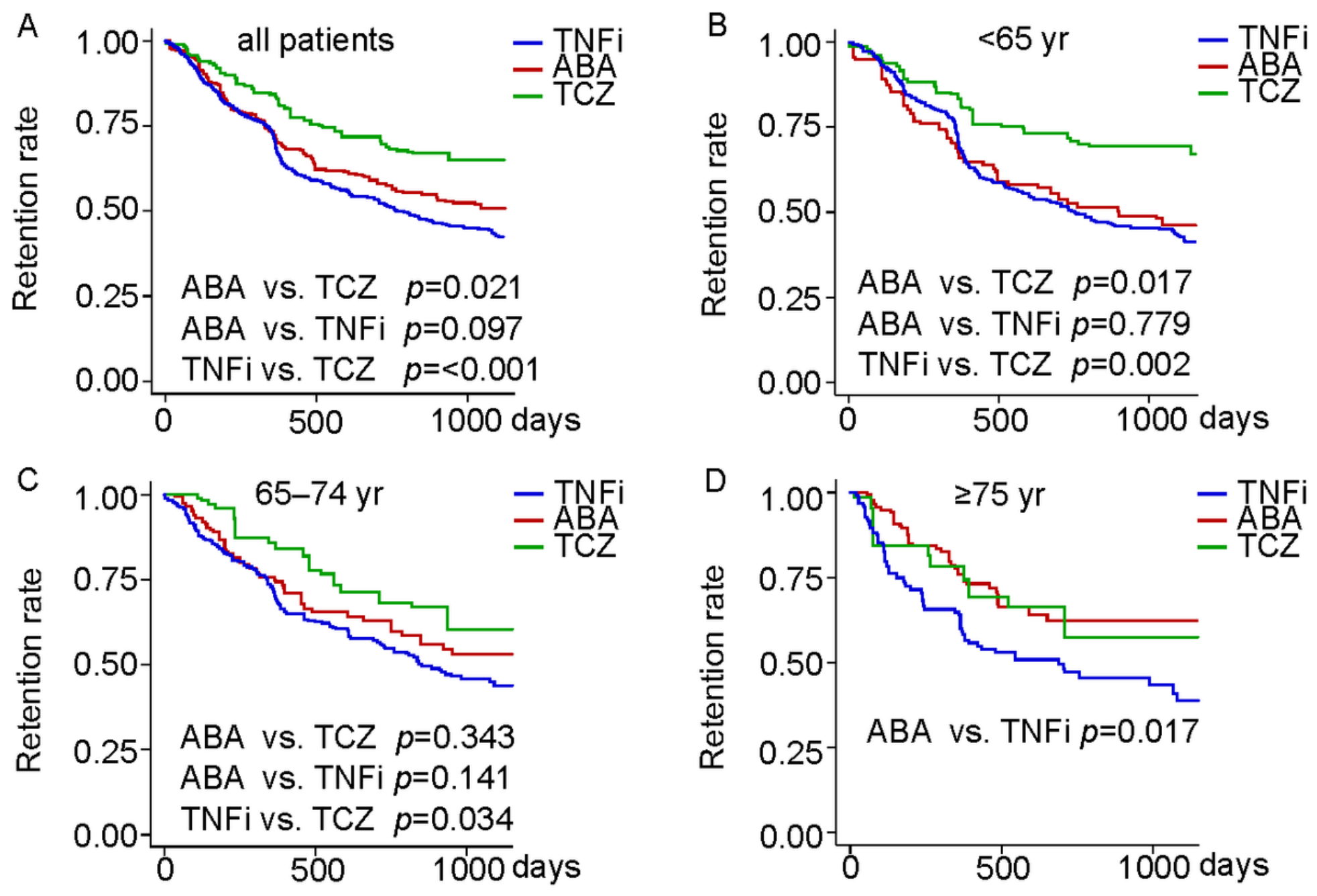

Figure 2

Three-year retention rates of bDMARDs in adjusted data using inverse probability of treatment weighting Three-year retention rates of bDMARDs in all patients $(A)$, in patients aged $<65$ years (B), in patients aged $65-74$ years (C), and in patients aged $\geq 75$ years $(D)$. $y r=$ years; $T N F i=$ tumor necrosis factor inhibitors; $A B A=$ abatacept; $T C Z=$ tocilizumab. 

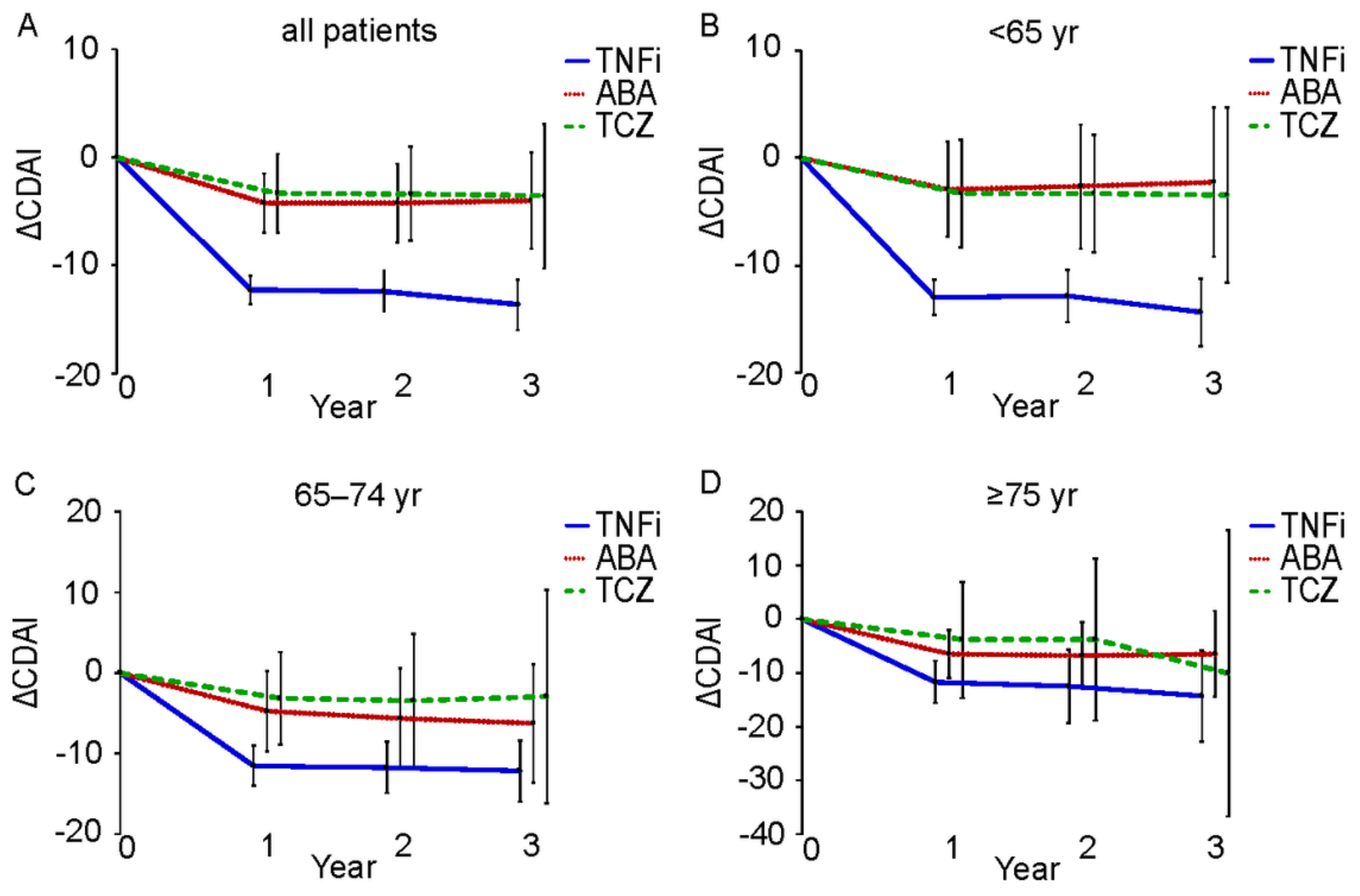

Figure 3

Changes in CDAl in adjusted data using inverse probability of treatment weighting Changes in CDAl in all patients (A), patients aged $<65$ years (B), patients aged $65-74$ years (C), and patients aged $\geq 75$ years (D). Data are presented as mean $\pm 95 \%$ confidence interval (error bars). $\mathrm{CDAI}=$ clinical disease activity index; $\mathrm{yr}=$ years; $\mathrm{TNFi}=$ tumor necrosis factor inhibitors; $A B A=$ abatacept; $T C Z$ = tocilizumab.

\section{Supplementary Files}

This is a list of supplementary files associated with this preprint. Click to download.

- SupplementaryMaterialAdditionalfile1.docx 